\title{
Loci and candidate genes conferring resistance to soybean cyst nematode HG type 2.5.7
}

Xue Zhao ${ }^{1 \dagger}$, Weili Teng ${ }^{1 \dagger}$, Yinghui Li , Dongyuan Liư ${ }^{3}$, Guanglu Cao ${ }^{1}$, Dongmei Li ${ }^{1}$, Lijuan Qiu², Hongkun Zheng ${ }^{3}$, Yingpeng $\mathrm{Han}^{1 *}$ and Wenbin $\mathrm{Li}^{1^{*}}$

\begin{abstract}
Background: Soybean (Glycine max L. Merr.) cyst nematode (SCN, Heterodera glycines $\left.I_{1}\right)$ is a major pest of soybean worldwide. The most effective strategy to control this pest involves the use of resistant cultivars. The aim of the present study was to investigate the genome-wide genetic architecture of resistance to SCN HG Type 2.5.7 (race 1) in landrace and elite cultivated soybeans.

Results: A total of 200 diverse soybean accessions were screened for resistance to SCN HG Type 2.5.7 and genotyped through sequencing using the Specific Locus Amplified Fragment Sequencing (SLAF-seq) approach with a 6.14-fold average sequencing depth. A total of 33,194 SNPs were identified with minor allele frequencies (MAF) over $4 \%$, covering $97 \%$ of all the genotypes. Genome-wide association mapping (GWAS) revealed thirteen SNPs associated with resistance to SCN HG Type 2.5.7. These SNPs were distributed on five chromosomes (Chr), including Chr7, 8, 14, 15 and 18. Four SNPs were novel resistance loci and nine SNPs were located near known QTL. A total of 30 genes were identified as candidate genes underlying SCN resistance.

Conclusions: A total of sixteen novel soybean accessions were identified with significant resistance to HG Type 2.5. 7. The beneficial alleles and candidate genes identified by GWAS might be valuable for improving marker-assisted breeding efficiency and exploring the molecular mechanisms underlying SCN resistance.
\end{abstract}

Keywords: Genome-wide association mapping, Soybean cyst nematode resistance, HG type 2.5.7, Candidate genes

\section{Background}

Soybean cyst nematode (SCN, Heterodera glycines Ichinohe) is the most economically important pest of soybean (Glycine $\max (\mathrm{L}$.) Merr.) [1]. The annual yield loss caused by $\mathrm{SCN}$ is $\$ 2$ billion [1]. Some agronomic management methods, such as non-host crop rotation and the use of chemical nematicides, may be used to control SCN. The most effective method still is the use of resistant cultivars [2]. However, most commercially available soybean cultivars exhibiting SCN resistance were primarily derived from plant introductions (PIs) 'PI88788,',PI209332,'‘PI548402' and 'Peking'. These PIs underlie 90\% of resistant cultivars [3].

\footnotetext{
* Correspondence: hyp234286@aliyun.com; wenbinli@neau.edu.cn ${ }^{\dagger}$ Equal contributors

${ }^{1}$ Key Laboratory of Soybean Biology in Chinese Ministry of Education (Key Laboratory of Soybean Biology and Breeding/Genetics of Chinese Agriculture Ministry), Northeast Agricultural University, Harbin 150030, China

Full list of author information is available at the end of the article
}

The continual use of so few resistance sources has led to SCN population shifts, resulting in new biotypes $[4,5]$. Hence, the selection of a new source of SCN resistance among soybean collections has been challenging.

The inheritance of SCN resistance is complicated [6-14]. The advance of DNA markers has enabled the detection of many quantitative trait loci (QTL) underlying resistance to SCN. To date, several putative QTL have been reported to be associated with resistance to SCN, derived from both cultivated and wild soybeans (Glycine soja) [7, 11-14]. These loci have provided resistance to various HG Types (previously races) and have been mapped onto 17 chromosomes (Chr) or linkage groups (LG). Among the identified QTL, rhg1 alleles a and b on Chr 18 and Rhg4 allele a on Chr 8 [7] were isolated from 'PI88788' and 'Forrest', respectively $[8,10]$. The copy number variation $(\mathrm{CNV})$ of $31 \mathrm{Kbp}$ DNA segment conferred the SCN resistance of $r h g 1$ allele $b$ 
in 'PI 88788' and three disparate genes presented on each repeat contribute to $\mathrm{SCN}$ resistance [8]. Differentially methylated DNA regions were also identified within rhg1, that correlate with soybean cyst nematode resistance [15]. Two point mutations in Rhg4 of 'Forrest' altered a key regulatory property of serine hydroxymethyltransferase. It had been hypothesized that this mutation might result in a nutritional deficiency among female nematodes [10].

SCN HG Type 2.5.7 (race 1) is prevalent in central US and China [16, 17], causing a severe yield loss of soybean. QTLs, associated with the resistance to SCN HG Type 2.5.7, have been identified through linkage mapping using segregating populations. Concibido et al. [18] initially identified QTL with resistance to SCN HG Type 2.5.7 in PI209332 [18]. Among the detected QTL, at least seven loci were identified as adjacent to rhg1. To date, most QTL associated with resistance to SCN HG Type 2.5.7 have been detected in North American resistance sources [7, 19], but Chinese resistance sources have been less well studied [1].

Genome-wide association analysis (GWAS), an alternative to linkage analysis, has been widely utilized to analyze the genetic architecture of important traits in crops, such as rice [20], wheat [21], barley [22] and soybean [17, 23]. The development of next-generation sequencing technology and single nucleotide polymorphism (SNP) genotyping technology have greatly promoted the applicability of GWAS [17]. Previously, we identified 19 association signals significantly associated with resistance to two SCN HG Types (HG Type 0 and HG Type 1.2.3.5.7) using 35,760 SNPs [23]. Zhang et al. [17] identified ten SNPs significantly associated with resistance to HG Type 2.5.7 using SoySNP50k iSelect BeadChip assays [17]. However, currently, genome-wide sequencing studies aimed at detecting QTL underlying the resistance to SCN HG Type 2.5.7 are lacking.

The aims of the present study were to identify new sources of HG2.5.7 resistance in 200 diverse soybean collections, primarily collected from China, to obtain insight into the genetic architecture of soybean resistance to SCN HG Type 2.5.7 using 33,194 SNPs and to predict potential candidate genes that might regulate SCN HG Type 2.5.7 resistance in the linked genomic region with peak SNPs.

\section{Methods}

\section{Genotyping of soybean germplasms}

A natural population, including 200 diverse soybean accessions, collected from inside and outside of China, was used for phenotypic evaluation and GWAS. Among the 200 soybean accessions, 179 accessions were selected from 2000 core germplasms, including 88 elite varieties, 35 elite lines and 56 landraces, representing the genetic and geographical diversity of soybean collections in China. The other twentyone accessions were collected from non-Chinese regions
(Additional file 1). These 200 soybean accessions were never tested for resistance to HG Type 2.5 .7 before. The genomic DNA of each accession was isolated from the fresh leaves of a single plant according to Wu et al. [24] and partially sequenced using specific locus amplified fragment sequencing (SLAF-seq) methodology [25, 26]. A double enzyme group, comprising Mse I (EC 3.1.21.4) and HaeIII (EC:3.1.21.4) (Thermo Fisher Scientific Inc., Waltham, MA, USA.), was used to digest the soybean genomic DNA into more than 50,000 sequencing tags (approximately 300-500 bp in length). The tags were evenly distributed in unique genomic regions. The sequencing libraries of each accession were constructed based on the sequencing tags. The 45-bp sequence read at both ends of the sequencing tags for each library was obtained using the barcode approach combined with the Illumina Genome Analyzer II (Illumina Inc., San Diego, CA, USA). The Short Oligonucleotide Alignment Program 2 (SOAP2) was used to map raw paired-end reads onto the reference genome (Glycine_max_Williams_82 $8 \times$ Release v1.01) [27]. The SLAF groups were obtained after sequencing reads with the same genomic position. Approximately 58,000 high-quality SLAF tags were obtained from each accession. In SNP calling, the MAF threshold was set at 0.04. The genotype was considered heterozygous when the depth of minor allele/ the total depth of the sample $\geq 1 / 3$.

\section{Evaluation of soybean germplasm resistance to SCN HG type 2.5 .7}

The 200 soybean accessions were used to evaluate the resistance to SCN HG Type 2.5.7 using a previously described inoculation method with minor modifications [23]. The soybean resistance to SCN HG Type 2.5.7 was evaluated in a completely randomized block design with three replications, and five plants in each replication were used, which was repeated twice. Thus, a total of 30 plants for each accession were used for phenotypic analyses. Thirty days after the accessions were inoculated, the cysts and females of the tested accessions were collected and measured. The female index was calculated as FI = (number of cysts and females on detected plant)/(average number of cysts and females on 'Lee 68') $\times 100$. FI > 10 and FI $<10$ was designated "+" and "-", respectively [28].

\section{Population structure evaluation and linkage disequilibrium (LD) analysis}

The population structure of the natural soybean population was analyzed using a principal component analysis (PCA) approach in the GAPIT software package [29]. The LD between pairs of SNPs was estimated using squared allele frequency correlations $\left(\mathrm{r}^{2}\right)$ in TASSEL version 3.0 [30]. Only SNPs with a MAF greater than 0.04 and missing data less than $10 \%$ were used to estimate LD. In contrast to the GWAS, missing SNP genotypes were not imputed with the 
major allele prior to LD analysis. Parameters in the program included MAF $(\geq 0.04)$ and the integrity of each SNP $(\geq 80 \%)$. $r$-square dropping to half of the maximum value was used to decay measure.

\section{Association mapping}

GLM in TASSEL [30], CMLM and ECMLM in GAPIT [29] were used to conduct GWAS based on 33,194 SNPs from 200 soybean accessions. The $p$ value was estimated using the Bonferroni's method at $\alpha \leq 0.01(\leq 3.01 \times 10$ $\left.{ }^{-7}\right)$ and $0.05\left(\leq 1.51 \times 10^{-6}\right)$, respectively, and set as the threshold to determine whether a significant association existed [31]. Candidate genes located within the LD block near a SNP peak were identified.

\section{Results}

\section{Susceptibility of soybean accessions to HG type 2.5.7} infection

The female index (FI) value of HG Type 2.5.7 exhibited a continuous distribution in the 200 soybean accessions. A wide range of variation from 0 to $478.7 \%$ was observed, with an average FI value of $104.2 \%$ (Additional file 1). The phenotypic data showed that sixteen soybean accessions exhibited significant resistance to HG Type 2.5.7. The square root function was used to normalize the phenotypic data of FI value. The kurtosis and skewness was -0.28 and 0.23 for repetition one and -0.48 and 0.28 for repetition two, respectively. The phenotype data of FI value showed near normal distribution after normalization (Fig. 1). The correlation coefficient ( $r$ ) of FI value of HG Type 2.5.7 between two repeated experiments was quite high, $r=0.91$ $(P<0.01)$. Thus, the average FI value of two repetitions was used as phenotypic data for GWAS.

\section{Distribution of markers and linkage disequilibrium}

A total of 33,194 SNPs, with minor allele frequencies (MAFs) $\geq 0.04$, were used to conduct GWAS with a marker density of $28.6 \mathrm{kbp}$ (Fig. 2, Additional file 2). The mean linkage disequilibrium (LD) was $212 \mathrm{kbp}$ (Fig. 3a).

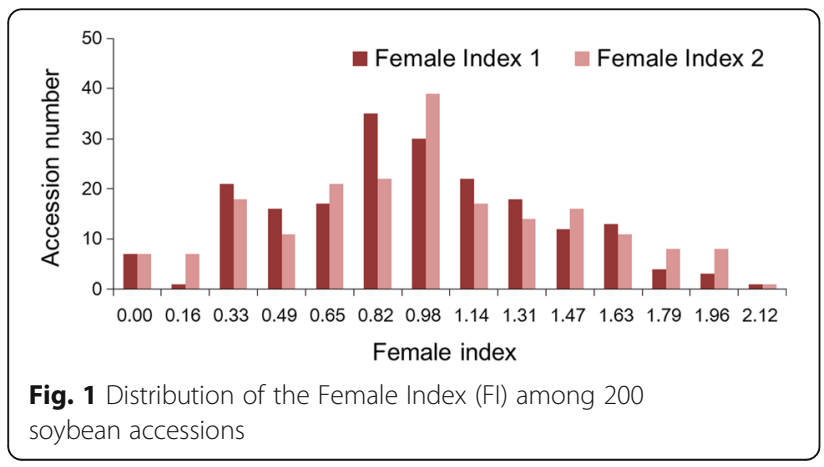

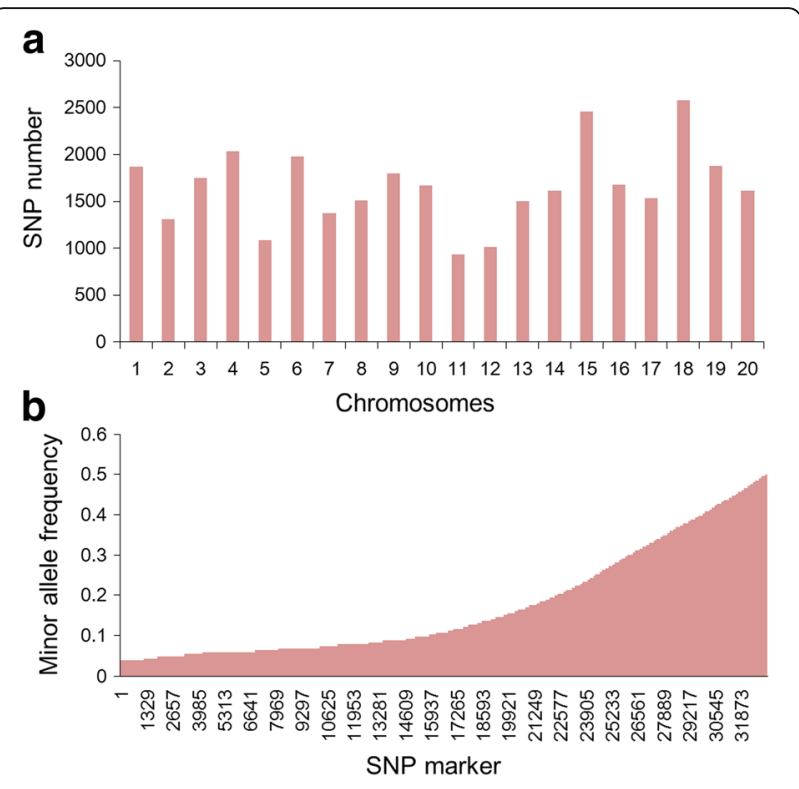

Fig. 2 Distribution of the SNP markers across 20 soybean chromosomes (a) and minor allele frequency distribution of SNP alleles (b)

\section{Quantitative trait nucleotide (QTN) associated with the resistance to HG type 2.5.7 identified by GWAS}

The generalized linear model (GLM) in the JAVA package, the Tassel [30], compressed mixed linear model (CMLM) and the enriched CMLM (ECMLM) model in the $R$ package GAPIT, were utilized in the present study [29]. In addition, a recently developed model selection algorithm [32] was also used. The CMLM and ECMLM considered both population structure and relative kinship [33, 34]. Principal component and kinship analyses were performed using the entire set of SNPs to capture the overall population stratification of the association panel. The first three PCs explained $16.3 \%$ of the total genetic variation (Fig. $3 \mathrm{~b}$ and c). A heatmap of the kinship matrix with genetic relatedness among the soybean accessions calculated from 33,194 SNPs used in the GWAS suggested low levels of relatedness among the 200 individuals (Fig. 3d). The quantile-quantile (QQ) plot showed that the observed $p$ values seriously deviated from the expected $p$ values for the GWAS result based on GLM method compared with that of the CMLM, ECMLM and FARMCPU methods (Fig. 4e-h). Since the observed and expected $P$-values differed substantially only for a few SNPs, the QQ plot supported the CMLM, ECMLM and FARMCPU as the appropriate GWAS models. Only involved population structures and kinship (CMLM, ECMLM and FARMCPU) showed significant control of the influence on the results of GWAS resulting from population structure and kinship. Therefore, the GWAS results using compressed MLM and FARMCPU methods were emphatically investigated. 

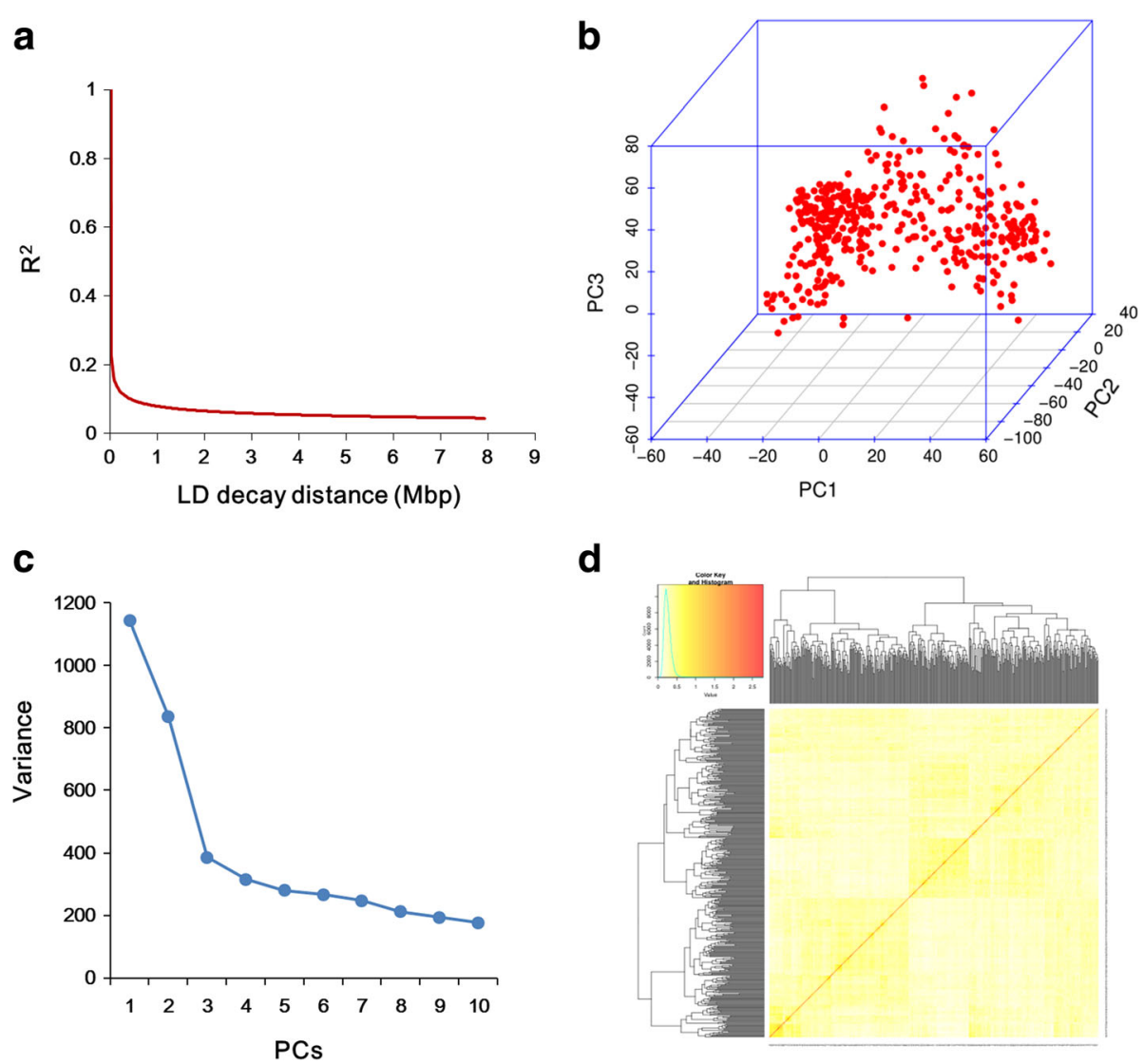

Fig. 3 The linkage disequilibrium (LD), principal component and kinship analyses of soybean genetic data. (a) The linkage disequilibrium (LD) decay of the genome-wide association study (GWAS) population. (b) The first three principal components of the 33,194 SNPs used in the GWAS indicated little population structure among the 200 tested accessions. (c) The population structure of the soybean germplasm collection reflected by principal components. (d) A heat map of the kinship matrix of the 200 soybean accessions calculated from the same 33,194 SNPs used in the GWAS, suggesting low levels of relatedness among the 200 individuals

Through GWAS, a total of thirteen SNPs were found to be associated with resistance to HG Type 2.5.7. Of them, ten SNPs were simultaneously detected using CMLM and ECMLM. Another three SNPs that located on Chr7, Chr 8 and Chr15 were detected under FARMCPU method (Table 1). The association signals were distributed on five chromosomes, including Chr7, Chr8, Chr14, Chr15 and Chr18. Among the ten significantly associated SNPs from CMLM and ECMLM, seven SNPs were located on Chr8. The other three SNPs were located on Chr18, Chr7 and Chr14, respectively. Four of the detected association signals were novel loci that were firstly found by the present study and another nine association signals overlapped with the known QTL underlying resistance to SCN (Table 2). Two stable loci, rs7671170 on Chr8 and rs46625879 on Chr18, were simultaneously identified using the three models. The effect of beneficial allele of each peak SNP associated with SCN resistance was analyzed. The result indicated that the average FI values of accessions with resistant alleles were significantly lower than that of the accessions with susceptible alleles for the all thirteen association signals. They were also lower than the average FI value of the whole association panel (Table 1). Therefore, these resistant alleles could be useful for markerassistant selection (MAS) of SCN resistance and these loci could be valuable for the isolation of candidate genes underlying the resistance to HG Type 2.5.7.

\section{Prediction of candidate genes for SCN resistance to HG type 2.5.7}

The candidate genes inferred to underlie resistance to HG Type 2.5.7 were evaluated. Genes located in the $200 \mathrm{kbp}$ genomic region of each peak SNP in the reference soybean genome (version a2.v1 of Williams 82, www. phetozome.net) were considered as candidate genes according to the average LD decay distance of $212 \mathrm{kbp}$ for the GWAS panel.

A total of 248 soybean genes were identified in the flanking region of each peak SNP (Additional file 3). Among these genes, 53 genes had no functional annotation, and seven genes belonged to the domains of unknown function families. To predict potential functions of genes in the flanking region of SNPs associated with the resistance to 

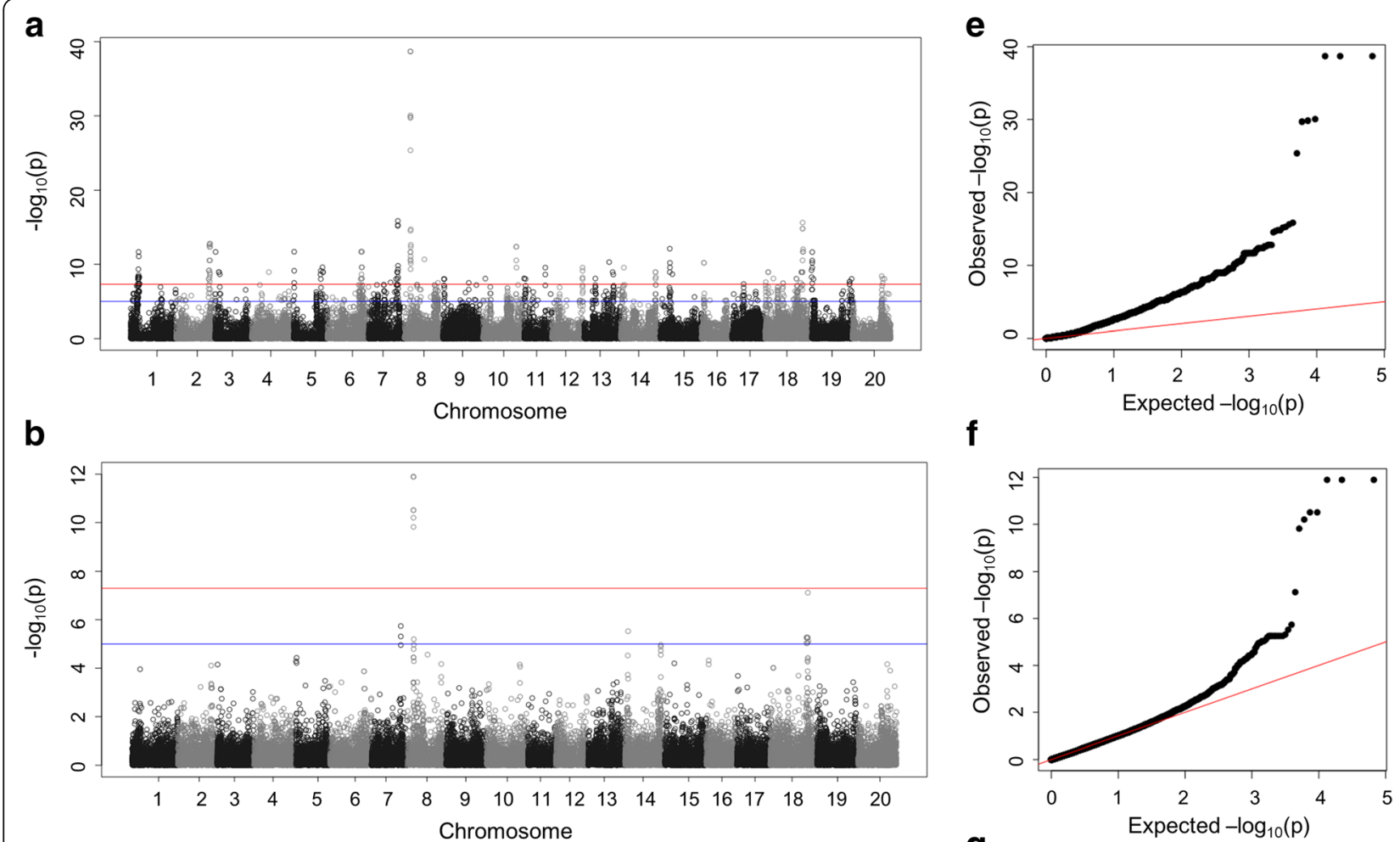

f

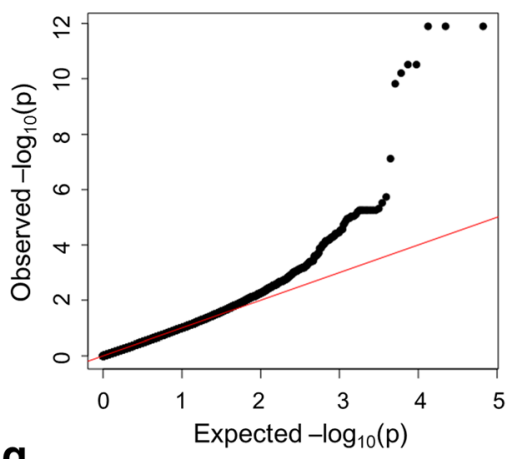

C

g
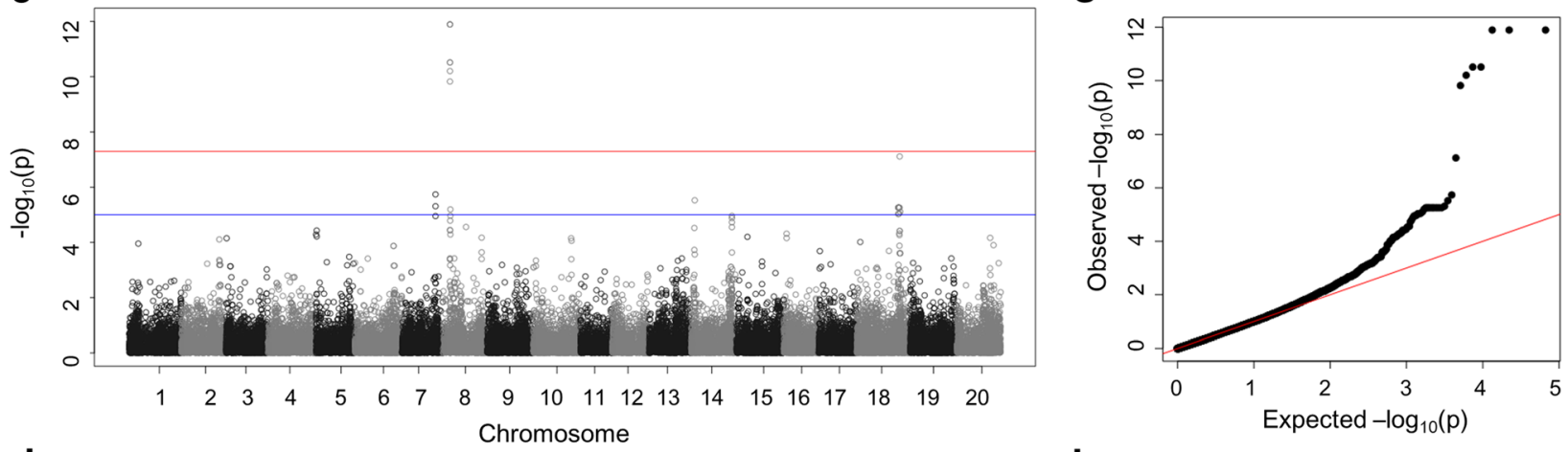

d

h
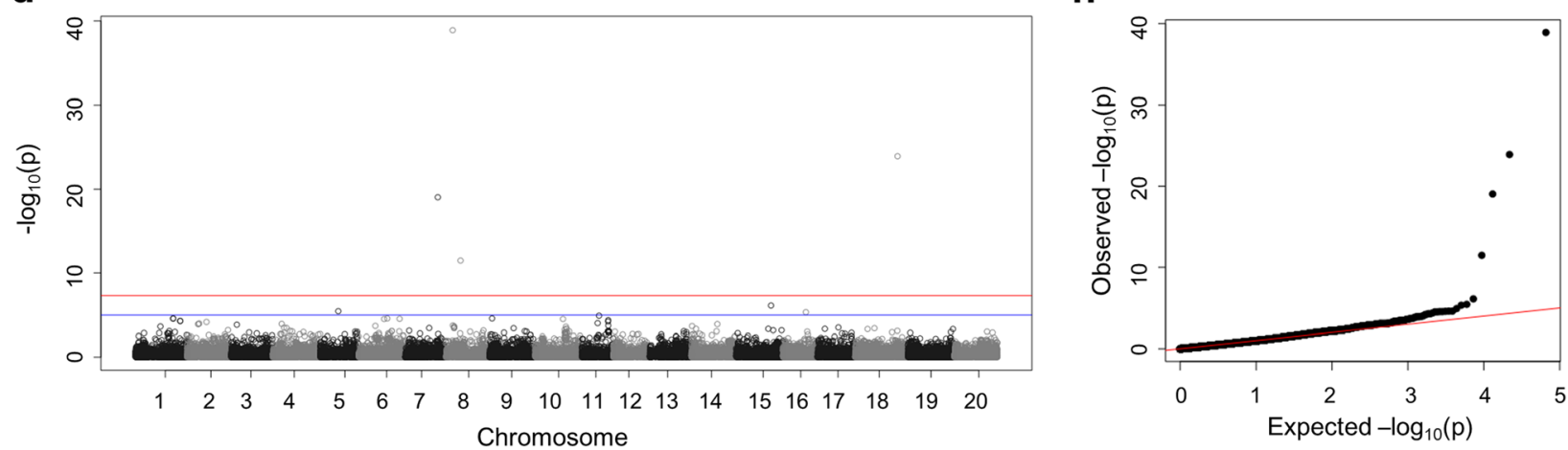

Fig. 4 Manhattan and QQ plots of GWAS for soybean susceptibility to HG Type 2.5.7. (a-d) Negative log 10-transformed $P$ values of SNPs from a genome-wide scan for soybean resistance to HG Type 2.5.7. were plotted against positions on each of the 20 chromosomes Under GLM, CMLM, ECMLM and FarmCPU models. The significant trait-associated SNPs were distinguished by the threshold line and colored in red and blue. (e-h) QQ plots of GWAS for soybean susceptibility to HG Type 2.5.7. under the above four models 
Table 1 Peak SNP and benefical allele associated with resistance to the Hg Type 2.5.7 (race 1) identified by GWAS

\begin{tabular}{|c|c|c|c|c|c|c|c|c|c|c|}
\hline SNP & Chromosome & Position & $-\log _{10}(p)$ & MAF & Model & $\begin{array}{l}\text { Resistant } \\
\text { allele }\end{array}$ & $\begin{array}{l}\text { Susceptible } \\
\text { alleles }\end{array}$ & $\begin{array}{l}\text { Average } \mathrm{Fl} \text { of } \\
\text { accessions with } \\
\text { resistant allele }\end{array}$ & $\begin{array}{l}\text { Average } \mathrm{Fl} \text { of } \\
\text { accessions with } \\
\text { susceptible allele }\end{array}$ & $\begin{array}{l}\text { Average } \mathrm{Fl} \\
\text { of } \\
\text { population }\end{array}$ \\
\hline rs7631207 & 8 & $7,631,207$ & 11.89 & 0.12 & CMLM & C & G & 22.71 & 111.07 & 104.19 \\
\hline rs7640250 & 8 & $7,640,250$ & 11.89 & 0.12 & CMLM & C & G & 22.71 & 111.07 & 104.19 \\
\hline rs7671170 & 8 & $7,671,170$ & 11.89 & 0.12 & CMLM & G & C & 22.71 & 111.07 & 104.19 \\
\hline rs7662003 & 8 & $7,662,003$ & 10.51 & 0.12 & CMLM & $\mathrm{T}$ & C & 39.36 & 110.13 & 104.19 \\
\hline rs7664479 & 8 & $7,664,479$ & 10.51 & 0.14 & CMLM & C & $A$ & 39.02 & 109.75 & 104.19 \\
\hline rs7622492 & 8 & $7,622,492$ & 10.2 & 0.11 & CMLM & A & G & 24.19 & 110.39 & 104.19 \\
\hline rs7661660 & 8 & $7,661,660$ & 9.82 & 0.12 & CMLM & C & A & 39.36 & 109.97 & 104.19 \\
\hline rs46625879 & 18 & $46,625,879$ & 7.12 & 0.1 & CMLM & G & T & 44.55 & 107.59 & 104.19 \\
\hline rs36423980 & 7 & $36,423,980$ & 5.74 & 0.17 & CMLM & A & G & 49.27 & 112.53 & 104.19 \\
\hline rs3853672 & 14 & $3,853,672$ & 5.53 & 0.1 & CMLM & A & T & 53.89 & 107.40 & 104.19 \\
\hline rs7631207 & 8 & $7,631,207$ & 11.89 & 0.12 & ECMLM & C & G & 22.71 & 111.07 & 104.19 \\
\hline rs7640250 & 8 & $7,640,250$ & 11.89 & 0.12 & ECMLM & C & G & 22.71 & 111.07 & 104.19 \\
\hline rs7671170 & 8 & $7,671,170$ & 11.89 & 0.12 & ECMLM & G & C & 22.71 & 111.07 & 104.19 \\
\hline rs7662003 & 8 & $7,662,003$ & 10.51 & 0.12 & ECMLM & $\mathrm{T}$ & $C$ & 39.36 & 110.13 & 104.19 \\
\hline rs7664479 & 8 & $7,664,479$ & 10.51 & 0.14 & ECMLM & C & A & 39.02 & 109.75 & 104.19 \\
\hline rs7622492 & 8 & $7,622,492$ & 10.2 & 0.11 & ECMLM & A & G & 24.19 & 110.39 & 104.19 \\
\hline rs7661660 & 8 & $7,661,660$ & 9.82 & 0.12 & ECMLM & C & A & 39.36 & 109.97 & 104.19 \\
\hline rs46625879 & 18 & $46,625,879$ & 7.12 & 0.1 & ECMLM & G & T & 44.55 & 107.59 & 104.19 \\
\hline rs36423980 & 7 & $36,423,980$ & 5.74 & 0.17 & ECMLM & A & G & 49.27 & 112.53 & 104.19 \\
\hline rs3853672 & 14 & $3,853,672$ & 5.53 & 0.1 & ECMLM & A & T & 53.89 & 107.40 & 104.19 \\
\hline rs7671170 & 8 & $7,671,170$ & 38.91 & 0.12 & FARMCPU & G & C & 22.71 & 111.07 & 104.19 \\
\hline rs46625879 & 18 & $46,625,879$ & 23.93 & 0.1 & FARMCPU & G & T & 44.55 & 107.59 & 104.19 \\
\hline rs35898587 & 7 & $35,898,587$ & 19.04 & 0.07 & FARMCPU & A & C & 48.30 & 107.38 & 104.19 \\
\hline rs16268025 & 8 & $16,268,025$ & 11.48 & 0.06 & FARMCPU & A & G & 71.46 & 106.50 & 104.19 \\
\hline rs38522986 & 15 & $38,522,986$ & 6.12 & 0.05 & FARMCPU & A & G & 52.14 & 107.16 & 104.19 \\
\hline
\end{tabular}

SCN, the 196 genes were grouped into the following functional categories using MapMap [35]: cell wall metabolism (eight genes), lipid metabolism (six genes), secondary metabolism (nine genes), biotic stress (five genes), signaling (nine genes), transcription regulation (transcription factors, TFs, 32 genes), hormonal metabolism (13 genes), redox group (two genes), protein modification and degradation (31 genes), transport (eight genes), development (two genes), DNA synthesis or chromatin structure (six genes), miscellaneous group (15 genes: 3 cytochrome P450 genes, 2 GDSL-motif lipase, 2 nitrile lyases etc.), light reaction (seven genes), other groups of genes (12 genes), and unclassified genes (12 genes) (Fig. 5). Of them, many genes have been implicated in plant disease defense or plant disease resistance pathways, including protein kinase family (belonging to the signal group), leucine-rich repeat-containing proteins and receptor-like protein. Some domain types, such as cytochrome P450s (belonging to the miscellaneous group), zinc fingers and RING (belonging to the transcription factors), have been implicated in soybean responses to
SCN [23]. To more accurately predict the candidate genes, the genes in a $50 \mathrm{kbp}$ genomic region of each side of the peak SNP were further selectively analyzed. A total of 21 candidate genes were eventually verified. Glyma.07G195500, encoding a transcription factor-related gene, was $12.78 \mathrm{kbp}$ away from SNP rs36423980 on Chr7. Glyma.07G195400 and Glyma.07G196000, with RING domains, were associated with SCN resistance. Gruenwald et al. reported that the auxin-inducible transcription factor AtWRKY23 was expressed during the infection of Arabidopsis roots with $H$. schachtii and demonstrated that the regulation of AtWRKY23 was controlled through auxin response factor 7 (ARF7) and the ARF19 pathway [36]. Herein, an auxin response factor gene (Glyma.08G100100) $2.4 \mathrm{kbp}$ from rs7671170 on Chr 8 was implicated in the soybean reaction to $\mathrm{SCN}$ infection. In the present study, Laccase genes (Glyma.18G193200, Glyma.18G193300, and Glyma.18G193400), which participate in lignin synthesis and phenolic compound metabolism in plants [37], might also contribute to HG Type 2.5.7 resistance in soybean. 
Table 2 Significant SNPS and predicted candidate genes associated with SCN HG Type 2.5.7 resistance in soybean

\begin{tabular}{|c|c|c|c|c|c|c|c|c|}
\hline SNP & Chr & Position & Model & QTLS & Gene & $\begin{array}{l}\text { Distance } \\
\text { to SNP } \\
\text { (Kbp) }\end{array}$ & Functional description & $\begin{array}{l}\text { Expression } \\
\text { pattern }\end{array}$ \\
\hline \multirow[t]{5}{*}{ rs35898587 } & \multirow[t]{5}{*}{7} & \multirow[t]{5}{*}{$35,898,587$} & \multirow[t]{5}{*}{ FARMCPU } & \multirow[t]{5}{*}{-} & Glyma.07G190900 & 46.68 & sphingosine kinase 1 & \\
\hline & & & & & Glyma.07G191000 & 42.52 & $\begin{array}{l}\text { Vacuolar protein sorting- } \\
\text { associated protein VPS28 family } \\
\text { protein }\end{array}$ & \\
\hline & & & & & Glyma.07G191100 & 33.66 & endonuclease 4 & \\
\hline & & & & & Glyma.07G191200 & 29.08 & $\begin{array}{l}\text { alternative } \mathrm{NAD}(\mathrm{P}) \mathrm{H} \\
\text { dehydrogenase } 2\end{array}$ & \\
\hline & & & & & Glyma.07G191500 & 2.12 & HAL2-like & \\
\hline \multirow[t]{6}{*}{ rs36423980 } & \multirow[t]{6}{*}{7} & \multirow[t]{6}{*}{$36,423,980$} & \multirow{6}{*}{$\begin{array}{l}\text { CMLM, } \\
\text { ECMLM }\end{array}$} & \multirow[t]{6}{*}{-} & Glyma.07G195400 & 28.22 & RING/U-box superfamily protein & \\
\hline & & & & & Glyma.07G195500 & 12.78 & transcription factor-related & \\
\hline & & & & & Glyma.07G196000 & 28.36 & RING membrane-anchor 1 & \\
\hline & & & & & Glyma.07G193900 & 174.20 & $\begin{array}{l}\text { Dof-type zinc finger DNA-binding } \\
\text { family protein }\end{array}$ & $\begin{array}{l}\text { regulated by } \\
\text { SCN }\end{array}$ \\
\hline & & & & & Glyma.07G196500 & 59.39 & phosphate 2 & $\begin{array}{l}\text { regulated by } \\
\text { SCN }\end{array}$ \\
\hline & & & & & Glyma.07G196800 & 85.03 & lipoxygenase 3 & $\begin{array}{l}\text { regulated by } \\
\text { SCN }\end{array}$ \\
\hline rs7631207 & 8 & $7,631,207$ & $\begin{array}{l}\text { CMLM, } \\
\text { ECMLM }\end{array}$ & \multirow{15}{*}{$\begin{array}{l}\text { Mattews et al. } 1998 \text { [40]; } \\
\text { Yuan et al. } 2002 \text { [42]; } \\
\text { Guo et al. } 2006 \text { [9]; } \\
\text { Vuong et al. } 2011 \text { [41] }\end{array}$} & Glyma.08G099400 & 24.52 & CBL-interacting protein kinase 23 & \\
\hline rs7640250 & 8 & $7,640,250$ & $\begin{array}{l}\text { CMLM, } \\
\text { ECMLM }\end{array}$ & & Glyma.08G099700 & 32.06 & $\begin{array}{l}\text { Metallo-hydrolase/oxidoreductase } \\
\text { superfamily protein }\end{array}$ & \\
\hline \multirow[t]{3}{*}{ rs7671170 } & \multirow[t]{3}{*}{8} & \multirow[t]{3}{*}{$7,671,170$} & \multirow{3}{*}{$\begin{array}{l}\text { CMLM, } \\
\text { ECMLM, } \\
\text { FARMCPU }\end{array}$} & & Glyma.08G100100 & 2.50 & auxin response factor 8 & \\
\hline & & & & & Glyma.08G100700 & 54.67 & RING/U-box superfamily protein & \\
\hline & & & & & Glyma.08G100800 & 60.21 & $\begin{array}{l}\text { Leucine-rich repeat protein } \\
\text { kinase family protein }\end{array}$ & \\
\hline rs7662003 & 8 & $7,662,003$ & $\begin{array}{l}\text { CMLM, } \\
\text { ECMLM }\end{array}$ & & & & & \\
\hline rs7664479 & 8 & $7,664,479$ & $\begin{array}{l}\text { CMLM, } \\
\text { ECMLM }\end{array}$ & & & & & \\
\hline rs7622492 & 8 & $7,622,492$ & $\begin{array}{l}\text { CMLM, } \\
\text { ECMLM }\end{array}$ & & Glyma.08G097300 & 184.48 & $\begin{array}{l}\text { Aldolase-type TIM barrel family } \\
\text { protein }\end{array}$ & $\begin{array}{l}\text { regulated by } \\
\text { SCN }\end{array}$ \\
\hline rs7661660 & 8 & $7,661,660$ & $\begin{array}{l}\text { CMLM, } \\
\text { ECMLM }\end{array}$ & & & & & \\
\hline \multirow[t]{6}{*}{ rs16268025 } & \multirow[t]{6}{*}{8} & \multirow[t]{6}{*}{$16,268,025$} & \multirow[t]{6}{*}{ FARMCPU } & & Glyma.08G200800 & 21.21 & $\begin{array}{l}\text { protein kinase family protein / } \\
\text { peptidoglycan-binding LysM } \\
\text { domain-containing protein }\end{array}$ & \\
\hline & & & & & Glyma.08G201000 & 9.76 & $\begin{array}{l}\text { hydroxyproline-rich glycoprotein } \\
\text { family protein }\end{array}$ & \\
\hline & & & & & Glyma.08G201100 & 1.89 & HPT phosphotransmitter 4 & \\
\hline & & & & & Glyma.08G200100 & 84.82 & $\begin{array}{l}\text { HAD superfamily, subfamily IIIB } \\
\text { acid phosphatase }\end{array}$ & $\begin{array}{l}\text { regulated by } \\
\text { SCN }\end{array}$ \\
\hline & & & & & Glyma.08G200200 & 80.21 & $\begin{array}{l}\text { HAD superfamily, subfamily IIIB } \\
\text { acid phosphatase }\end{array}$ & $\begin{array}{l}\text { regulated both } \\
\text { constitutively } \\
\text { and by SCN }\end{array}$ \\
\hline & & & & & Glyma.08G202300 & 57.12 & $\begin{array}{l}\text { Integrase-type DNA-binding } \\
\text { superfamily protein }\end{array}$ & $\begin{array}{l}\text { regulated by } \\
\text { SCN }\end{array}$ \\
\hline \multirow[t]{2}{*}{ rs3853672 } & \multirow[t]{2}{*}{14} & \multirow[t]{2}{*}{$3,853,672$} & \multirow[t]{2}{*}{$\begin{array}{l}\text { CMLM, } \\
\text { ECMLM }\end{array}$} & \multirow[t]{2}{*}{-} & Glyma.14G048600 & 74.83 & $\begin{array}{l}\text { disease resistance protein (TIR- } \\
\text { NBS-LRR class), putative }\end{array}$ & \\
\hline & & & & & Glyma.14G049500 & 15.54 & ethylene-forming enzyme & \\
\hline
\end{tabular}


Table 2 Significant SNPs and predicted candidate genes associated with SCN HG Type 2.5.7 resistance in soybean (Continued)

\begin{tabular}{|c|c|c|c|c|c|c|c|c|}
\hline & & & & & Glyma.14G047900 & 179.55 & $\begin{array}{l}\text { Leucine-rich repeat receptor-like } \\
\text { protein kinase family protein }\end{array}$ & $\begin{array}{l}\text { regulated by } \\
\text { SCN }\end{array}$ \\
\hline & & & & & Glyma.14G051600 & 196.06 & Copper transport protein family & $\begin{array}{l}\text { regulated by } \\
\text { SCN }\end{array}$ \\
\hline rs38522986 & 15 & $38,522,986$ & FARMCPU & Kabelka et al. 2005 [43] & & & & \\
\hline \multirow[t]{3}{*}{ rs46625879 } & \multirow[t]{3}{*}{18} & \multirow[t]{3}{*}{$46,625,879$} & \multirow{3}{*}{$\begin{array}{l}\text { CMLM, } \\
\text { ECMLM, } \\
\text { FARMCPU }\end{array}$} & \multirow[t]{3}{*}{ Winter et al. 2007 [12] } & Glyma.18G193200 & 65.89 & laccase 7 & \\
\hline & & & & & Glyma.18G193300 & 49.11 & laccase 8 & \\
\hline & & & & & Glyma.18G193400 & 3.01 & $\begin{array}{l}\text { Laccase/Diphenol oxidase family } \\
\text { protein }\end{array}$ & \\
\hline
\end{tabular}

Note: the expression pattern was according to Wan et al. BMC Genomics [39]

Ithal et al. tested three time points after SCN feeding $(2,5$, and $10 \mathrm{dpi}$ ) and also noted an increase in the expression of genes involved in lignin biosynthesis and phenolic compound metabolism [38]. Except for the above genes, nine genes out of the 196 were regulated by SCN in different soybean lines according to the report by Wan et al. [39]. Of them, Leucine-rich repeat receptor-like protein kinase family protein (Glyma.14G047900) might be involved in SCN resistance since the gene showed up-regulated after SCN inoculation (Table 2) [39].

\section{Discussion}

$\mathrm{SCN}$ is estimated to cause the greatest yield loss in soybean compared with other pests worldwide [7]. Genes conferring durable resistance to SCN might exist in the soybean germplasms of China, where soybean originated [23]. In the present study, a total of 200 soybean accessions primarily collected inside China were tested. Among these accessions, 16 accessions showed high resistance to SCN HG Type 2.5.7, most of which were landraces with specific elite agronomic traits. Therefore, these resistance sources have great potential value for future breeding for SCN resistance.

To date, numbers of SCN-resistant QTL have been reported [7]. Most of which were verified using different cross populations from limited resistance sources. Two major QTL across multiple resistant sources were rhg1 and Rhg4 [7]. Additionally, QTL qSCN11, located on Chr11, has also been consistently identified from PI 437654, PI 90763 and PI 404198B [2]. In the present study, a total of thirteen SNPs distributed on five chromosomes (Chr 7, 8, 14, 15 and 18) were associated with SCN HG Type 2.5.7 resistance. Among the thirteen association signals, nine SNPs overlapped with or were located near known QTL (Table 2). A resistant genomic region in Chr8, containing the gene loci of rs7631207, rs7640250, rs7671170, rs7662003, rs7664479, rs7622492 and rs7661660, were significantly associated with SCN resistance to HG Type 2.5.7, and the relation between these genomic regions and SCN resistance has been reported in previous studies [9, 40-42]. Similarly, two SNPs, rs38522986 and rs46625879, located on Chr15 and Chr18, respectively, were identified inside two marker intervals previously reported by Kabelka et al. [43] and Winter et al. [12]. Moreover, two genomic regions (rs7671170 on Chr8 and rs46625879 on Chr18) could stably be identified using three models, including CMLM, ECMLM and FARMCPU, which further verified the importance of these two genomic regions for resistance to HG Type 2.5.7. These consistent genomic regions in the present and previous studies showed that Chr8, Chr15 and Chr18 might play important

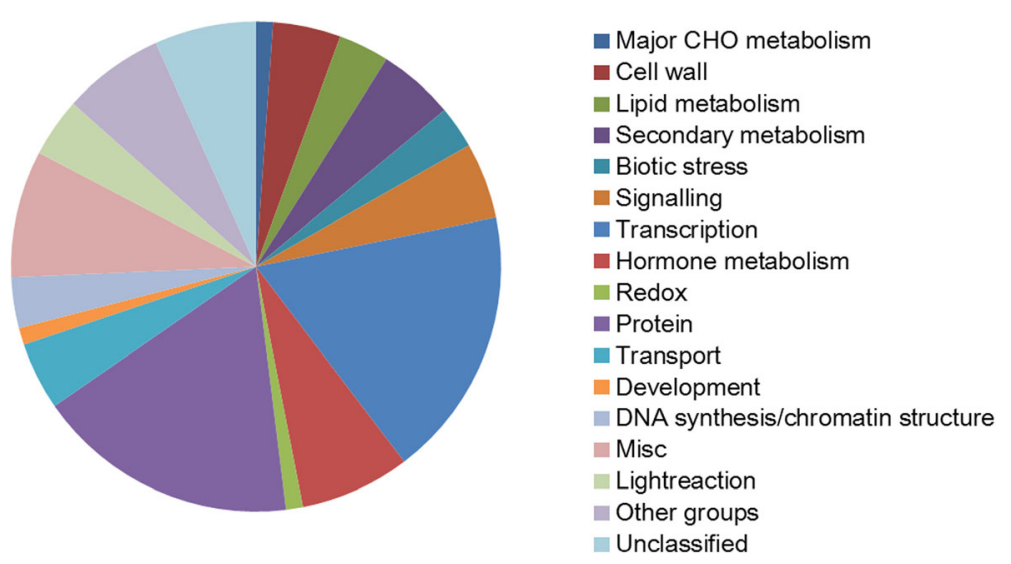

Fig. 5 Functional categories of the predicted resistant genes to HG Type 2.5.7 
roles in conferring $\mathrm{SCN}$ resistance in the soybean germplasms of China and North America.

Major QTL, rhg1 and Rhg4, were valuable resources for $\mathrm{SCN}$ resistance, but were frequently not durable, reflecting shifts in the SCN population that resulted in a loss of SCN resistance in major QTL [2]. Breeding soybean with durable resistance to SCN through the identification and utilization of novel QTL is an effective strategy to cope with the loss of SCN resistance [2]. One novel QTL on Chr10 (qSCN10) was identified in PI 567516C [4], which could confer high SCN resistance to soybean lacking the two known major genes, rhg1 and Rhg4. Additionally, four novel QTL (rs35898587 and rs36423980 on Chr7, rs16268025 on Chr8, and rs3853672 on Chr14) were also identified, which were significantly different from the major QTL reported in previous studies. Although the molecular mechanisms of the novel resistance loci were not clear, these loci possessed high potential to breed cultivars with durable resistance to SCN through the pyramid of the novel and previously reported QTL [7].

Presently, for the molecular mechanism of SCN resistance genes, only two genes, $r h g 1$ and $R h g 4$, were clearly associated with the molecular mechanism of SCN resistance $[8,10]$, and other candidate genes or QTL underlying SCN resistance were less investigated. Thus, it was difficult to predict and confirm the SCN candidates from large QTL intervals with a number of genes. However, GWAS could still offer some valuable clues to identify and confirm SCN resistance genes, particularly within a linkage disequilibrium (LD) block (150-200 kbp in length on average) [23, 44]. In the present study, a total of 196 potential candidate genes, located in $200 \mathrm{kbp}$ flanking regions up- and downstream of thirteen peak SNPs, possessed the canonical SCN resistance domains (including cytochrome P450s, zinc fingers and RING) [23], which are involved in plant disease responses or plant disease resistance pathways. Among these candidate genes, six genes (Glyma.07G195400, Glyma.07G196000, Glyma.08G100100, Glyma.18G193200, Glyma.18G193300 and Glyma.18G193400) have been reported to be responsible for SCN resistance [23]. Furthermore, 15 novel genes (Glyma.07G190900, Glyma.07G191000, Glyma.07G191100, Glyma.07G191200, Glyma.07G191500, Glyma.07G195500, Glyma.08G099400, Glyma.08G099700, Glyma.08G100700, Glyma.08G100800, Glyma.08G200800, Glyma.08G201000, Glyma.08G201100, Glyma.14G048600, and Glyma.14G049500), located in 50 kbp flanking regions up- and downstream of peak SNPs, were associated with SCN HG Type 2.5.7 resistance in the present study. The clear function of these candidates should be discussed in future studies.

\section{Conclusions}

A total of sixteen novel soybean accessions were identified with significant resistance to HG Type 2.5.7. The multiple beneficial alleles and candidate genes from novel resistant germplasms might be valuable for the breeding of cultivars with long-lasting resistance to $\mathrm{SCN}$.

\section{Additional files}

Additional file 1: Source and phenotype data of 200 soybean accessions.

Additional file 2: SNP list of 200 soybean accessions. (7Z 1043 kb)

Additional file 3: Gene models in the flanking regions of peak SNP. (XLSX 26 kb)

\section{Abbreviations}

CMLM: Compressed mixed linear model; ECMLM: enriched compressed mixed linear model; GLM: General linear model; GWAS: Genome-wide association study; LD: Linkage disequilibrium; MAF: Minor allele frequency; PCA: principal component analysis; QTL: Quantitative Trait Locus:;

SCN: Soybean cyst nematode; SLAF-seq: Specific Locus Amplified Fragment Sequencing; SNPs: Single nucleotide polymorphisms

\section{Acknowledgments}

This study was conducted in the Key Laboratory of Soybean Biology of the Chinese Education Ministry, the Soybean Research \& Development Center (CARS) and the Key Laboratory of Northeastern Soybean Biology and Breeding/Genetics of the Chinese Agriculture Ministry.

\section{Funding}

This study was financially supported through nine sources of grants. The National Key R\&D Project for Crop Breeding (2016YFD0100300) and Heilongjiang Provincial Natural Science Foundation (C2015011) contributed to the design of the study.

The National Supporting Project (2014BAD22B01), the Youth Leading Talent Project of the Ministry of Science and Technology in China (2015RA228), the National Natural Science Foundation of China $(31471517,31671717)$ and the 'Academic Backbone' Project of Northeast Agricultural University (15XG04) offer the help for the collection, analysis, and interpretation of data. The "Young Talents" Project of Northeast Agricultural University (14QC27) and the Postdoctoral Fund in Heilongjiang Province (LBH-Z15017) provided the support for writing the manuscript and publication charge.

\section{Availability of data and materials}

The data generated or analyzed during this study are included in this published article and its supplementary information files.

\section{Authors' contributions}

WBL designed and supervised the research; XZ and GLC conducted the field trial to evaluate SCN resistance; WLT and DML conducted the molecular experiments; $X Z$, DYL and YPH analyzed the data; and XZ, YPH, YHL, LJQ, HKZ and WBL drafted the manuscript. All authors have read and approved the manuscript.

\section{Competing interests}

The authors declare that they have no competing interests.

\section{Consent for publication}

Not applicable.

Ethics approval and consent to participate

The plant materials were collected from germplasms bank of the Key Laboratory of Soybean Biology of the Chinese Education Ministry. The collection and usage of samples followed the ethics of the People's Republic of China.

\section{Publisher's Note}

Springer Nature remains neutral with regard to jurisdictional claims in published maps and institutional affiliations. 


\section{Author details}

'Key Laboratory of Soybean Biology in Chinese Ministry of Education (Key Laboratory of Soybean Biology and Breeding/Genetics of Chinese Agriculture Ministry), Northeast Agricultural University, Harbin 150030, China. Institute of Crop Science, National Key Facility for Crop Gene Resources and Genetic Improvement (NFCRI), Chinese Academy of Agricultural Sciences, Beijing 100081, China. ${ }^{3}$ Bioinformatics Division, Biomarker Technologies Corporation, Beijing 101300, China

Received: 19 January 2017 Accepted: 5 June 2017

Published online: 14 June 2017

\section{References}

1. Wrather J, Koenning S. Estimates of disease effects on soybean yields in the United States 2003 to 2005. J Nematol. 2006;38(2):8.

2. Kadam S, Vuong TD, Qiu D, Meinhardt CG, Song L, Deshmukh R, et al. Genomicassisted phylogenetic analysis and marker development for next generation soybean cyst nematode resistance breeding. Plant Sci. 2016;242:342-50.

3. Winter SMJ, Rajcan I, Shelp BJ. Soybean cyst nematode: challenges and opportunities. Can J Plant Sci. 2006;86(1):25-32.

4. Vuong T, Sleper D, Shannon J, Nguyen H. Novel quantitative trait loci for broad-based resistance to soybean cyst nematode (Heterodera glycines Ichinohe) in soybean PI 567516C. Theor Appl Genet. 2010;121(7):1253-66.

5. Diers BW. R-AP: management of parasitic nematodes of soybean through genetic resistance. Chicago: Champaign; 1999.

6. Concibido V, Denny R, Boutin S, Hautea R, Orf J, Young N. DNA marker analysis of loci underlying resistance to soybean cyst nematode (Heterodera glycines Ichinohe). Crop Sci. 1994;34(1):240-6.

7. Concibido VC, Diers BW, Arelli PR. A decade of QTL mapping for cyst nematode resistance in soybean. Crop Sci. 2004;44(4):1121-31.

8. Cook DE, Lee TG, Guo X, Melito S, Wang K, Bayless AM, et al. Copy number variation of multiple genes at Rhg1 mediates nematode resistance in soybean. Science. 2012;338

9. Guo B, Sleper DA, Nguyen HT, Arelli PR, Shannon JG. Quantitative trait loci underlying resistance to three soybean cyst nematode populations in soybean PI 404198A. Crop Sci. 2006;46(1):224-33.

10. Liu S, Kandoth PK, Warren SD, Yeckel G, Heinz R, Alden J, et al. A soybean cyst nematode resistance gene points to a new mechanism of plant resistance to pathogens. Nature. 2012;492:256-60.

11. Qiu BX, Arelli PR, Sleper DA. RFLP markers associated with soybean cyst nematode resistance and seed composition in a 'Peking' $X^{\prime} E s s e x$ ' population. Theor Appl Genet. 1999;98(3):356-64.

12. Winter SJ, Shelp B, Anderson T, Welacky T, Rajcan I. QTL associated with horizontal resistance to soybean cyst nematode in Glycine soja PI464925B. Theor Appl Genet. 2007;114(3):461-72.

13. Yue $P$, Arelli PR, Sleper DA. Molecular characterization of resistance to Heterodera glycines in soybean PI 438489B. Theor Appl Genet. 2001;102(6):921-8.

14. Yue P, Sleper DA, Arelli PR. Mapping resistance to multiple races of in soybean PI 89772. Crop Sci. 2001;41(5):1589-95.

15. Cook DE, Bayless AM, Wang K, Guo X, Song Q, Jiang J, et al. Distinct copy number, coding sequence, and locus methylation patterns underlie Rhg1mediated soybean resistance to soybean cyst nematode. Plant Physiol. 2014;165(2):630-47.

16. Chang W, Dong L, Wang Z, Hu H, Han Y, Teng W, et al. QTL underlying resistance to two $H G$ types of Heterodera glycines found in soybean cultivar 'L-10'. BMC Genomics. 2011;12:233.

17. Zhang H, Li C, Davis EL, Wang J, Griffin JD, Kofsky J, et al. Genome-wide association study of resistance to soybean cyst nematode (Heterodera glycines) HG type 2.5.7 in wild soybean (Glycine soja). Front Plant Sci. 2016:7:1214.

18. Concibido VC, Denny RL, Lange DA, Orf JH, Young ND. RFLP mapping and marker-assisted selection of soybean cyst nematode resistance in PI 209332. Crop Sci. 1996;36(6):1643-50

19. Arelli PR, Sleper DA, Yue P, Wilcox JA. Soybean reaction to races 1 and 2 of Heterodera glycines. Crop Sci. 2000:40(3):824-6.

20. Huang X, Wei X, Sang T, Zhao Q, Feng Q, Zhao Y, et al. Genome-wide association studies of 14 agronomic traits in rice landraces. Nat Genet. 2010; 42(11):961-7.

21. Raman H, Stodart B, Ryan PR, Delhaize E, Emebiri L, Raman R, et al. Genome-wide association analyses of common wheat (Triticum aestivum L.) germplasm identifies multiple loci for aluminium resistance. Genome. 2010;53(11):957-66.
22. Cockram J, White J, Zuluaga DL, Smith D, Comadran J, Macaulay M, et al. Genome-wide association mapping to candidate polymorphism resolution in the unsequenced barley genome. Proc Natl Acad Sci U S A. 2010;107(50):21611-6.

23. Han Y, Zhao X, Cao G, Wang Y, Li Y, Liu D, et al. Genetic characteristics of soybean resistance to $\mathrm{HG}$ type 0 and $\mathrm{HG}$ type 1.2.3.5.7 of the cyst nematode analyzed by genome-wide association mapping. BMC Genomics. 2015;16(1):598.

24. Wu X, Ren C, Joshi T, Vuong T, Xu D, Nguyen H. SNP discovery by highthroughput sequencing in soybean. BMC Genomics. 2010;11(1):469.

25. Sun X, Liu D, Zhang X, Li W, Liu H, Hong W, et al. SLAF-seq: an efficient method of large-scale de novo SNP discovery and genotyping using highthroughput sequencing. PLoS One. 2013;8(3):e58700

26. Han Y, Zhao X, Liu D, Li Y, Lightfoot DA, Yang Z, et al. Domestication footprints anchor genomic regions of agronomic importance in soybeans. New Phytol. 2016:209(2):871-84.

27. Li R, Yu C, Li Y, Lam T-W, Yiu S-M, Kristiansen K, et al. SOAP2: an improved ultrafast tool for short read alignment. Bioinformatics. 2009;25(15):1966-7.

28. Golden A, Epps J, Riggs R, Duclos L, Fox J, Bernard R. Terminology and identity of infraspecific forms of the soybean cyst nematode (Heterodera glyecines'). Plant Dis Report. 1970;54(7):544-6.

29. Lipka AE, Tian F, Wang Q, Peiffer J, Li M, Bradbury PJ, et al. GAPIT: genome association and prediction integrated tool. Bioinformatics. 2012;28(18):2397-9.

30. Bradbury PJ, Zhang Z, Kroon DE, Casstevens TM, Ramdoss Y, Buckler ES. TASSEL: software for association mapping of complex traits in diverse samples. Bioinformatics. 2007;23(19):2633-5.

31. Holm S. A simple sequentially rejective multiple test procedure. Scand J Stat. 1979;6(2):65-70

32. Liu X, Huang M, Fan B, Buckler ES, Zhang Z. Iterative usage of fixed and random effect models for powerful and efficient genome-wide association studies. PLoS Genet. 2016:12(2):e1005767.

33. Li M, Liu X, Bradbury P, Yu J, Zhang Y-M, Todhunter RJ, et al. Enrichment of statistical power for genome-wide association studies. BMC Biol. 2014;12(1):1-10.

34. Zhang Z, Ersoz E, Lai CQ, Todhunter RJ, Tiwari HK, Gore MA, et al. Mixed linear model approach adapted for genome-wide association studies. Nat Genet. 2010;42(4):355-60.

35. Thimm O, Bläsing $O$, Gibon $Y$, Nagel A, Meyer $S$, Krüger $P$, et al. MAPMAN: a user-driven tool to display genomics data sets onto diagrams of metabolic pathways and other biological processes. Plant J. 2004;37(6):914-39.

36. Grunewald W, De Smet I, Lewis DR, Löfke C, Jansen L, Goeminne G, et al. Transcription factor WRKY23 assists auxin distribution patterns during Arabidopsis root development through local control on flavonol biosynthesis. Proc Natl Acad Sci U S A. 2012;109(5):1554-9.

37. Klink VP, Matthews BF. Emerging approaches to broaden resistance of soybean to soybean cyst nematode as supported by gene expression studies. Plant Physiol. 2009;151(3):1017-22.

38. Ithal N, Recknor J, Nettleton D, Hearne L, Maier T, Baum TJ, et al. Parallel genome-wide expression profiling of host and pathogen during soybean cyst nematode infection of soybean. Mol Plant Microbe In. 2007:20(3):293-305.

39. Wan J, Vuong $T$, Jiao $Y$, Joshi $T$, Zhang $H, X u ~ D$, et al. Whole-genome gene expression profiling revealed genes and pathways potentially involved in regulating interactions of soybean with cyst nematode (Heterodera glycines Ichinohe). BMC Genomics. 2015;16:148.

40. Matthews BF, MacDonald MH, Gebhardt JS, Devine TE. Molecular markers residing close to the Rhg4 locus conferring resistance to soybean cyst nematode race 3 on linkage group a of soybean. Theor Appl Genet. 1998; 97(7):1047-52

41. Vuong T, Sleper D, Shannon J, Wu X, Nguyen H. Confirmation of quantitative trait loci for resistance to multiple-HG types of soybean cyst nematode (Heterodera glycines Ichinohe). Euphytica. 2011;181(1):101-13.

42. Yuan J, Njiti VN, Meksem K, lqbal MJ, Triwitayakorn K, Kassem MA, et al. Quantitative trait loci in two soybean recombinant inbred line populations segregating for yield and disease resistance this research was suported by Illinois soybean program operating board (ISPOB) grants 95-222-24-3 and 98-222-25-2. Crop Sci. 2002:42(1):271-7.

43. Kabelka EA, Carlson SR, Diers BW. Localization of two loci that confer resistance to soybean cyst nematode from Glycine soja PI 468916. Crop Sci. 2005;45(6):2473-81.

44. Lam HM, Xu X, Liu X, Chen W, Yang G, Wong FL, et al. Resequencing of 31 wild and cultivated soybean genomes identifies patterns of genetic diversity and selection. Nat Genet. 2010:42(12):1053-9. 